\title{
Motivation Factors Driving Travel Intention in the Controlled Pandemic Context: Perspectives from Malaysian and Taiwanese Travellers
}

\author{
Christopher Wan Sageng'; Hiram Ting ${ }^{1,2^{*}}$; Hsuan-Hsuan Chang ${ }^{2,1}$; Choi-Meng \\ Leong $^{3}$ and Hui-Bun Ting ${ }^{1}$
}

${ }^{I}$ Faculty of Hospitality and Tourism Management, UCSI University, Malaysia

${ }^{2}$ Department of Leisure and Recreation Management, Ming Chuan University, Taiwan

${ }^{3}$ UCSI Graduate Business School, UCSI University, Malaysia

*Corresponding author: hiramparousia@gmail.com

\begin{abstract}
Travelling is considered one of the best ways to escape one's day-to-day routine activities. Tourists' travel is driven by several motivational factors, which lead them to plan or continue on a travel trip. However, since the emergence of COVID-19, travelling has become a major issue for the whole travel industry. The recent spread of Omicron makes most post-pandemic studies futile. Therefore, the purpose of this study was to examine the influence of motivation factors that affect tourists' travel intention in the controlled pandemic context. The mediating role of perceived value and the moderating role of perceived travel risk were examined as well. The Stimulus-Organism-Response (S-O-R) theory was adopted as the theoretical foundation of the research framework. A quantitative online survey was used to collect data from 388 Malaysian and Taiwanese travelers. Partial least squares structural equation modelling (PLS-SEM) was employed to analyse the data. The results show that escape, kinship, and people are direct and indirect motivation factors that influence tourists' intention to travel via perceived value. Notably travel risk indicated no moderating effect. The results of this study provide useful insights into tourists' post-pandemic behaviour that offer practical implications for Asian business.
\end{abstract}

Keywords: Motivation, Malaysia, Taiwan, Perceived value, Travel risk, Controlledpandemic behaviour. 


\section{Introduction}

Since its inception in late-2019, the coronavirus (COVID-19) pandemic has ravaged the world, affecting the communities of all nations and causing severe economic disruptions (Davies, 2020). Statistics show that as of November 2021, over 270 million confirmed cases had been identified throughout the world, with over five million deaths (Worldometer, 2021). Multiple efforts have since been made by societies to minimise the transmission of the disease, including complete or partial lockdowns, stringent limits on big group gatherings in open or private areas, and restrictions on people's movement and the performance of services (UNWTO, 2020). This is because public or large-scale forms of transport, such as aircraft, buses, and trains, are considered as main risk points for the spread of the pandemic and are therefore the first to require precautionary actions (Turnsek et al., 2020).

In particular, the travel and tourism industry has been among the worst hit by the outbreak (OECD, 2020). During the height of the pandemic, countries under lockdown, like Malaysia, restricted foreign tourists from visiting or attending business meetings. Consequently, most airlines grounded their flights and travel declined (Connor, 2020). Travelers also refused to fly and tourism operations were suspended, resulting in significant negative impact to the industry (Khan, 2020). However, not every country undergoes the same situations. Since the acute respiratory syndrome (SARS) outbreak in 2003, Taiwan has been well-prepared and on standby to react to the pandemic. On $19^{\text {th }}$ May 2021, Taiwan reported its highest number of cases in a day, which was 543 (Worldometer, 2021). It is a stark difference from that of Malaysia with the highest number of confirmed cases per day which was 24,599 cases recorded on $26^{\text {th }}$ August 2021. Notwithstanding the rolling out of vaccination programs and partial opening of international borders, there are still concerns about the spread of COVID-19 through different variants. As such, multiple measures are taken and renewed by countries, including Malaysia and Taiwan, to ensure tourism recovery and traveling will not invite another large-scale outbreak.

Most studies focus on the current effects of COVID-19 or its detrimental effects on different sectors of the economy (Brouder et al., 2020; Gössling et al., 2020; Goodell, 2020; Nicola et al., 2020). Moreover, there is a growing number of studies looking into the rising indication of market recovery and tourists' willingness travel again. Besides, previous research has also investigated the impact of tourists' demographic factors and travel motivation on their destination choice and travel intention (Kara \& Mkwizu, 2020; Yoo et al., 2018). These studies suggest the use of the push-and-pull model and the Travel Career Ladder (TCL) as underlying theories to examine the motivation factors of travel intention. This study, in turn, is conducted to examine the travel intention of Malaysians and Taiwanese travelers when the pandemic is under control. Under control refers to the period when the spread of COVID-19 is relatively contained with health and safety measures in place and the border restrictions relaxed, thus allowing travel and tourism sectors to resume their activities in stages.

As evidenced in the literature, perceived value has often been associated to behavioural intention (Cham et al., 2020; Cham et al., 2021a). A number of studies have also been conducted on travelers' perception of risk in terms of health crises like SARS (Pine \& McKercher, 2004), H1N1 (Lee et al., 2012), and Ebola (Cahyanto et al., 2016). Considering the controlled pandemic context, this study proposed the inclusion of 
perceived value and perceived travel risk as the mediating and moderating factors respectively in a motivation-intention framework. Such addition of knowledge is necessary given the inexorable plans and policies to restart tourism activities when the variants of COVID-19, such as Delta and Omicron, remain a threat. Using Malaysia and Taiwan as the context, the purpose of the present study is to provide greater insights for tourism scholars, destinations marketers, travel organisations, and other relevant stakeholders to comprehend the interlinks between motivation factors, perceived value, perceived travel risk and travel intention in an uncertain, dilemmalike and precarious situation.

\section{Literature Review}

\section{Underpinning Theory: S-O-R Theory}

The present research adopted the Stimulus-Organism-Response (S-O-R) model as the underpinning theory to support the research framework. As evident from its name, the S-O-R model is made up of three fundamental elements: stimulus, organism, and response (Lee \& Yun, 2015), wherein people's organismic or internal processes play a mediating role between external stimuli and people's responses to those stimuli (Mehrabian \& Russell, 1974). In general, the organism is viewed as a subjective experience activated by external factors, while the response is the outcome that can be divided into either actions of resistance or actions of approach (Chen et al., 2020). The $\mathrm{S}-\mathrm{O}-\mathrm{R}$ model therefore claims that the organism and response are affected by the stimulus (Lee \& Yun, 2015).

This model has been applied in several research contexts, such as retail (Lee \& Yun, 2015; Cham et al., 2021b), online customer behaviour and product satisfaction (Hu et al., 2016; Xiao et al., 2019), and behavioural intention based on past travel experience (Chen et al., 2020; Cheng et al., 2021). However, its adoption in the tourism field of travel intention based on travel motivation is limited, especially from the perspective of the current pandemic. In view of this, the S-O-R model was adopted in the current research to explore why Malaysians and Taiwanese travel when the pandemic is under control. In this study, the Stimulus is represented by travel motivation (S), the Organism is represented by perceived value and perceived risk in travelling $(\mathrm{O})$, and the Response is represented by the intention to travel $(\mathrm{R})$. Based on this conceptualisation, it is anticipated that the S-O-R model offers a strong theoretical foundation for developing an integrated model that can elucidate the link between tourists' travel motivation and travel intention via perceived value and perceived risk.

\section{Perceived Value (O)}

Perceived value reflects the relative trade-off between the cost the consumer sacrifices for a good or service and the advantages the consumer obtains from the good or service. In other words, perceived value is the benefit an individual believes he/she gains by purchasing products or services. According to Prebensen and Xie (2017), perceived value is a complex and dynamic term made up of social value, functional value, philosophical value, and a sense of well-being. The relationship between consumers and service providers is greater if consumers believe they can obtain greater benefits from their financial and non-financial expenditures, which ultimately influence their 
future choices (Zufara \& Fitriya, 2019; Suhartanto et al., 2019). From the travel perspective, perceived value can be viewed as tourists' perception of worth in going on a trip or the positive gains that can be obtained through the trip. Evidence of the impact of perceived value on customer involvement with products and services has been wellestablished in past studies (García-Fernández et al., 2018; Lim et al., 2019).

\section{Motivation to Travel}

Travel motivation is an internal force that stimulates a person to choose a specific destination to achieve desired rewards and fulfilment (Pyo \& Uysal, 1989). According to Iso-Ahola (1982), motivation is a sociopsychological force that drives a person to visit a new location and participate in recreational activities. Beard and Ragheb's (1983) theory has been adopted in a past research to investigate the effect of motivational factors on tourists' satisfaction with recreational activities (Kara \& Mkwizu, 2020). The factors included were mastery competence motivation, social motivation, intellectual motivation, and stimulus avoidance motivation (Beard \& Ragheb, 1983). Another study used pleasure motivation to determine the relationship between motivation, intercultural contact, and cultural attitudes (Fisher \& Price, 1991). Moreover, motivation factors have also been found to have a significant direct effect on tourists' perceptions of value and risk in their travel decisions. Hence, the present study examined the effect of five motivation factors (i.e., education, escape, coping, kinship, and people) on tourists' perceived value and travel intention. It is anticipated that such findings will provide a more detailed understanding of individuals' motivations at the psychological level with regard to their future travel intention.

Education motivation is the desire to be open to learning, tolerant of cultural differences, and appreciative of the unique characteristics of different communities (Dann, 1981). Thus, it reflects an individual's aspiration to learn, accept, and value various cultures and ethnicities in other regions and countries. If this desire is strong, a traveller is likely to plan a trip to gain cultural knowledge. It is argued that the sense of "curiosity" within tourists could motivate them to the quest for cognitive stimulation, that is, the desire for experience and knowledge about a destination (Totsune et al., 2021). Apart from that, the urge to explore the knowledge of a destination can also help travellers to understand the destination better and have a direct impact on their perception towards the image of the destination which will subsequently influence their intention to travel (Cham et al., 2021a).

Escape motivation is the desire to forget a certain situation or an encountered problem by escaping or taking a break from daily routines (Crompton, 1979). In fact, Iso-Ahola (1982) claimed that a significant reason for leisure travel is often to escape from one's daily schedule and pressures. According to Shanmugam et al. (2020), COVID-19 has had a negative impact on the mental health of the population. For example, in May 2020, a woman aged 56 in Kuching, Malaysia fell to her death from the seventh floor of her condominium likely due to depression, based on the self-inflicted cuts on her neck and hands (Dayak Daily, 2020). It was further discovered that the woman loved to travel but could not do so due to the pandemic and the Movement Control Order (MCO) in Malaysia, which may have worsened her mental condition. 
Coping motivation is similar to escape motivation but implies a different meaning. While escape motivation refers to running away from burdens or responsibilities, coping motivation is the desire to use a trip to promote psychological adaptation or analytical thinking (Fisher \& Price, 1991). Individuals may wish to develop a clearer objective view of what has happened around them by travelling to different places.

Tinsley and Kass (1978) mentioned that a travel trip may be the result of travellers' desire to connect or engage socially. In this regard, kinship and people motivations are both seen as forms of social interaction. Kinship motivation is exhibited by people who travel to connect with friends, family, and community members who are part of the same travelling group during the holiday experience (Woodside \& Jacobs, 1985). On the other hand, people motivation refers to the ability to connect with people of the host community. In this scenario, tourists are drawn by the thrill and total strangeness of direct interaction with new individuals from different cultures (Cohen, 1972).

Based on the above discussion, it is expected that the motivation factors highlighted above are likely to influence the way tourists perceive the value of their trip. As such, the following hypotheses were postulated:

H1 Education motivation is positively related to perceived value.

H2 Escape motivation is positively related to perceived value.

H3 Coping motivation is positively related to perceived value.

H4 Kinship motivation is positively related to perceived value.

H5 People motivation is positively related to perceived value.

\section{Travel Intention}

Peter and Olson (1996) suggest that consumers' behaviours are based on their assumptions about the advantages of taking a specific action (e.g., purchasing a product or travelling to a desired location), which influences their subjective evaluation of whether to participate in that action. According to Dann (1981), travel motivation is a fundamental primary force underlying travel behaviour. It is generally induced by push and pull factors which shape customers' attitudes towards travel products and services. Past studies have mostly examined how travel motivation leads to destination choice using the TCL theory (Yoo et al., 2018) or the push-and-pull model (Khan et al., 2017). In this study, the S-O-R theory is applied instead, with travel intention representing the response, $(\mathrm{R})$. This model is suitable because of the present research's focus on how travel motivation influences travel intention in general, with no specific destination choice. The study also incorporated perceived value as a mediator that explains the effects of motivation factors on travel intention. Therefore, the SOR theory clarifies the process through which travel motivation (S) stimulates the underlying evaluation process of perceived value $(\mathrm{O})$ to develop the outcome of tourist travel intention $(\mathrm{R})$. Supporting this idea, the prior literature shows that perceived value is a mediator of satisfaction and action-oriented behaviour (Prebensen \& Xie, 2017). When a traveller is motivated to travel to a destination, he/she may perceive more value to be gained from travelling and consequently, develop a stronger intention to travel. Based on this 
discussion, the following hypotheses were proposed:

H6a Perceived value mediates the relationship between education motivation and intention to travel.

H6b Perceived value mediates the relationship between escape motivation and intention to travel.

H6c Perceived value mediates the relationship between coping motivation and intention to travel.

H6d Perceived value mediates the relationship between kinship motivation and intention to travel.

H6e Perceived value mediates the relationship between people motivation and intention to travel.

\section{Perceived Travel Risk}

Perceived risk has been described as a personal analysis of the risks of a dangerous situation based on its traits and seriousness (Neuburger \& Egger, 2021). This analysis or judgement of risk can vary depending on an individual's personal characteristics, social systems, and cultural values (Boholm, 1998). In turn, how one interprets risk perception can affect his/her attitude (Weinstein, 1988). In tourism, risk perception is related to the evaluation of the potential risks (from economic, psychological, threatrelated, and duration-related aspects) arising from planning, purchasing, and consuming travel services or experiences (Sönmez, 1998). Maser and Weiermair (1998) defined travel risks as natural hazards, sanitation and diseases, violations, and injuries. A number of studies have investigated travellers' risk perception in terms of health crises like SARS (Pine \& McKercher, 2004), H1N1 (Lee et al., 2012), and Ebola (Cahyanto et al., 2016). Meanwhile, relatively less research has examined the influence of COVID-19 on the perceived travel risk and travel intention of tourists. Thus, this research sought to determine how tourists' perceived risk of travelling when the pandemic is under control affects their travel intention.

Uncertainty is considered a reason for perceived risk when buying products or using services (Shin \& Kang, 2020). Hofstede's (2001) Uncertainty Avoidance Theory discusses a community's acceptance of ambiguity and uncertainty. In particular, it shows the degree to which a culture shapes its people to feel either nervous or relaxed in unstructured environments. Situations that are ambiguous are unusual, unfamiliar, shocking, and abnormal. Correspondingly, the perceived risk of travelling is the uncertainty or ambiguity viewed by an individual about a trip, which can be expressed as changing travel plans, travelling only to a specific place or country, or avoiding specific destinations (Sönmez \& Graefe, 1998). Tourists typically prefer to avoid locations which are normally considered to be unsafe or high risk; rather, they select locations which are more likely to be secure. Therefore, perceived risk does not only affect an individual's travel plans but also the intention to travel in the first place. The occurrence of the pandemic and its severe effects may now be perceived as a risk in travelling, which can weaken individuals' travel intention despite the perceived value of the trip. 
H7 When perceived travel risk is high, it weakens the relationship between perceived value and travel intention.

Referring to the review of the literature and its gaps, the research model for this study is shown in Figure 1.

Figure 1: Research Model

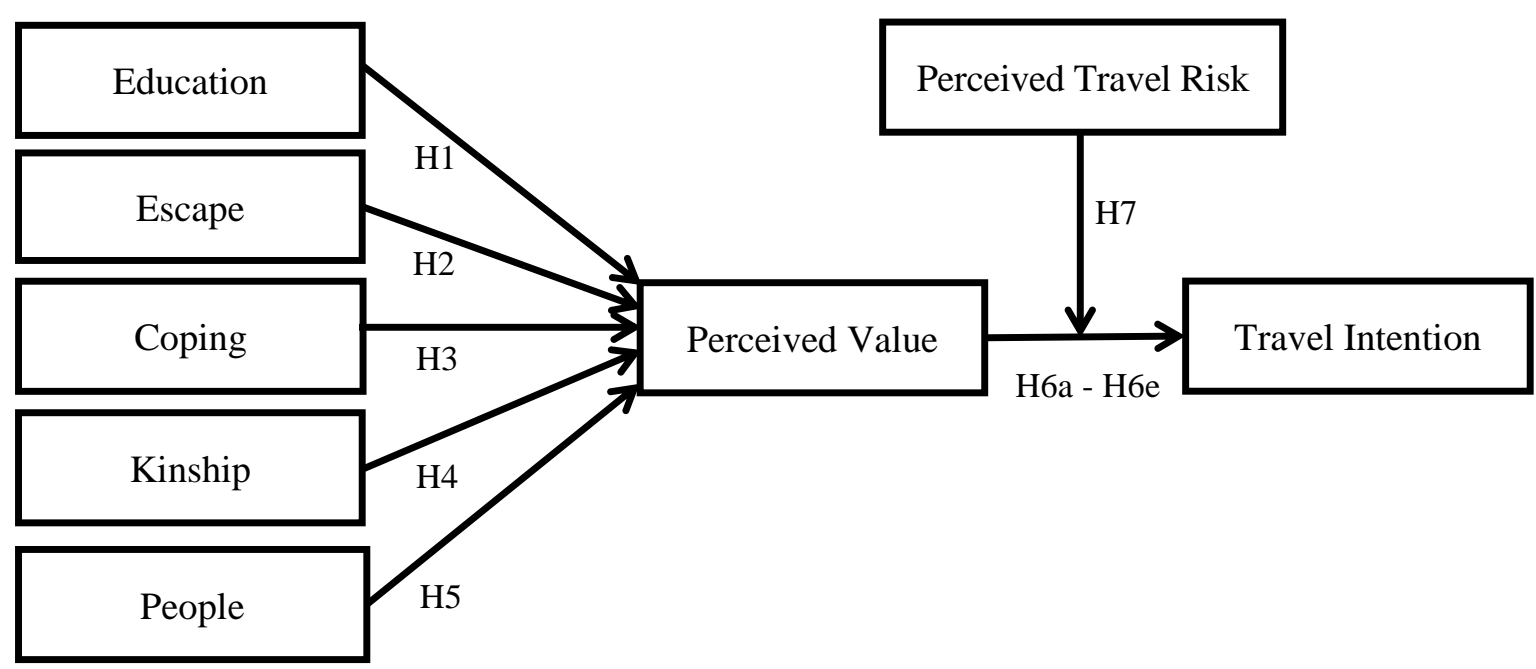

\section{Research Methodology}

\section{Sampling Procedure and Data Collection}

The target population of this study were Malaysian and Taiwanese citizens. A selfadministered survey questionnaire was employed to collect data from 400 respondents through an online survey platform, i.e., Google Form. According to Saunders et al. (2012), the sample size of 400 is considered adequate for this study to represent a large population. As per Cohen (1988), we further determined the minimum sample size requirement for this study using the G*Power software. Drawing from Faul et al.'s (2009) suggestion, the $\mathrm{G}^{*}$ Power output revealed a minimum requirement of 138 samples at a minimum effect size of 0.15 , a statistical power level of $80 \%$, and a significance level of $5 \%$. The total sample size of 388 for this study was, therefore, considered more than sufficient. To generate reliable responses, the purposive sampling technique was applied in the data collection process to determine the suitability of the respondents before they participated in the study. The criteria for respondents were: (1) must be 18 years old and above; (2) have travelled at least once in their lifetime; and (3) have travelled before by car, airplane, ship, bus, or train. The survey questionnaire took the respondents approximately 15 minutes to complete.

\section{Measurement}

The measurement items for the constructs were adapted from past studies with slight modifications to better reflect the context of the study. A five-point Likert scale (with 1 representing strongly disagree and 5 representing strongly agree) was used to measure 
all the items. The developed questionnaire was pre-tested and pilot tested as part of its preliminary validity assessment. The measurement items for all constructs are listed in Table 1.

Table 1: Constructs and Measurement

\begin{tabular}{|c|c|c|}
\hline Constructs & Items & Measurement \\
\hline \multirow[t]{4}{*}{ Education } & EDU1 & Learn about different cultures. \\
\hline & EDU2 & Increase my knowledge of different places. \\
\hline & EDU3 & Be intellectually enriched. \\
\hline & EDU4 & Increase my knowledge of different communities. \\
\hline \multirow[t]{4}{*}{ Escape } & ESC1 & Forget about everything else. \\
\hline & $\mathrm{ESC} 2$ & Take a break. \\
\hline & ESC3 & Take my mind off daily routines. \\
\hline & ESC4 & Take my attention away from my workloads \\
\hline \multirow[t]{4}{*}{ Coping } & COP1 & Evaluate the perspectives of my life. \\
\hline & COP2 & Take an objective view of what has happened around me. \\
\hline & COP3 & Try to see a bigger picture of some aspects of my life. \\
\hline & COP4 & Help me make better decisions for my life. \\
\hline \multirow[t]{4}{*}{ Kinship } & KIN1 & Allow me as much time as possible with friends and family. \\
\hline & KIN2 & Surround myself with people who are significant to me. \\
\hline & KIN3 & Be with people who are important to me. \\
\hline & KIN4 & Help strengthen ties with family or friends. \\
\hline \multirow[t]{4}{*}{ People } & PEO1 & Meet new people. \\
\hline & PEO2 & Interact with new people. \\
\hline & PEO3 & Make more friends. \\
\hline & PEO4 & Get to know people who are different from myself. \\
\hline \multirow[t]{3}{*}{$\begin{array}{l}\text { Perceived } \\
\text { Value }\end{array}$} & TPV1 & $\begin{array}{l}\text { Travelling is good 'value for money' when the pandemic is under } \\
\text { control. }\end{array}$ \\
\hline & TPV2 & $\begin{array}{l}\text { When the pandemic is under control, spending time to travel will } \\
\text { be worthwhile. }\end{array}$ \\
\hline & TPV3 & $\begin{array}{l}\text { Travelling will bring more benefits than costs to me when the } \\
\text { pandemic is under control. }\end{array}$ \\
\hline Perceived & PTR1 & The spread of coronavirus through travelling still worries me. \\
\hline \multirow{3}{*}{ Travel Risk } & PTR2 & The movements of locals and foreigners may spread the virus. \\
\hline & PTR3 & I am concerned that some travellers are carrying the virus. \\
\hline & PTR4 & Travelling increases my chances of contracting the virus. \\
\hline Travel & TIN1 & I plan to travel when movement control is further eased. \\
\hline \multirow{2}{*}{ Intention } & TIN2 & I will travel when the pandemic is no longer serious. \\
\hline & TIN3 & $\begin{array}{l}\text { I intend to travel when border restrictions between states and } \\
\text { countries are removed. }\end{array}$ \\
\hline
\end{tabular}

\section{Data Analysis}

The proposed research model was estimated using partial least squares structural equation modelling (PLS-SEM) through the SmartPLS 3.0 software (Sarstedt \& Cheah, 2019). PLS-SEM is useful in providing explanations and predictions of the phenomena under investigation (Chin et al., 2020). It has also been found to perform robustly when assessing complex relationships involving both mediation and moderation analyses in the model. 


\section{Demographic Profile}

Table 2 presents the demographic profile of the respondents who participated in this study. The nationalities of the respondents (i.e., Malaysian and Taiwanese) were equally distributed. A majority of the respondents were females (66.8\%) and in the age group of 21 to 30 years old $(49.2 \%)$. Moreover, most of the respondents (63.1\%) were full-time workers.

Table 2: Respondents' Demographic Profile $(n=388)$

\begin{tabular}{llcc}
\hline Variables & Descriptions & Frequency & Percentage \\
\hline Nationalities & Malaysian & 199 & 51.3 \\
& Taiwanese & 189 & 48.7 \\
Gender & Female & 259 & 66.8 \\
& Male & 129 & 33.2 \\
Age & $21-30$ & 191 & 49.2 \\
& $31-40$ & 40 & 10.3 \\
& $41-50$ & 61 & 15.7 \\
& $51-60$ & 66 & 17 \\
Employment & 31 and above & 124 & 7.7 \\
& Students & 245 & 32 \\
& Full-time Workers & 19 & 63.1 \\
& Others & & 4.9 \\
\hline
\end{tabular}

\section{Assessment of Reflective Measurement Model}

According to Table 3, all the constructs for each group of respondents were highly reliable and internally consistent based on Cronbach's alpha and Composite Reliability (CR) values, which were all above 0.70 . The lowest value of Cronbach's alpha and CR were 0.817 and 0.890 , respectively. Moreover, Table 4 shows the results of convergent validity, presented as factor loadings and Average Variance Extracted (AVE). The data shows that the factor loading values exceeded the threshold value of 0.708. Likewise, all AVE values were above the minimum required value of 0.5 . Both results imply that all the items were strongly linked to weighing their construct, thereby establishing convergent validity.

As for discriminant validity, Table 5 presents the results of the Heterotrait-Monotrait Ratio of Correlations (HTMT) for both groups of respondents. The data shows that all values were below the threshold value of 0.85 , confirming that the items measured only their assigned construct. The items of different constructs were not connected to each other; therefore, discriminant validity was achieved. 
Table 3: Assessment of Internal Reliability

\begin{tabular}{ccccccc}
\hline \multirow{2}{*}{ Constructs } & \multicolumn{2}{c}{ Cronbach's Alpha } & \multicolumn{3}{c}{ Composite Reliability } \\
& OVERALL & $M A S$ & $T W N$ & OVERALL & $M A S$ & TWN \\
\hline COP & 0.916 & 0.894 & 0.932 & 0.941 & 0.926 & 0.952 \\
EDU & 0.917 & 0.916 & 0.917 & 0.941 & 0.940 & 0.941 \\
ESC & 0.875 & 0.868 & 0.882 & 0.915 & 0.910 & 0.920 \\
KIN & 0.894 & 0.915 & 0.881 & 0.925 & 0.940 & 0.918 \\
PEO & 0.941 & 0.947 & 0.937 & 0.958 & 0.962 & 0.955 \\
PTR & 0.951 & 0.961 & 0.944 & 0.964 & 0.971 & 0.955 \\
TPV & 0.866 & 0.862 & 0.856 & 0.918 & 0.916 & 0.913 \\
TIN & 0.844 & 0.817 & 0.869 & 0.906 & 0.890 & 0.920 \\
\hline
\end{tabular}

Note: MAS = Malaysians; TWN = Taiwanese

Table 4: Assessment of Convergent Validity

\begin{tabular}{|c|c|c|c|c|c|c|}
\hline \multirow{2}{*}{ Items } & \multicolumn{3}{|c|}{ Factor Loadings } & \multicolumn{3}{|c|}{ Average Variance Extracted } \\
\hline & OVERALL & $M A S$ & $T W N$ & OVERALL & $M A S$ & $T W N$ \\
\hline COP1 & 0.905 & 0.859 & 0.940 & \multirow{4}{*}{0.798} & \multirow{4}{*}{0.757} & \multirow{4}{*}{0.832} \\
\hline $\mathrm{COP} 2$ & 0.898 & 0.898 & 0.899 & & & \\
\hline COP3 & 0.892 & 0.869 & 0.908 & & & \\
\hline $\mathrm{COP} 4$ & 0.879 & 0.852 & 0.899 & & & \\
\hline EDU1 & 0.884 & 0.868 & 0.896 & \multirow{4}{*}{0.800} & \multirow{4}{*}{0.797} & \multirow{4}{*}{0.800} \\
\hline EDU2 & 0.897 & 0.877 & 0.912 & & & \\
\hline EDU3 & 0.879 & 0.897 & 0.866 & & & \\
\hline EDU4 & 0.918 & 0.928 & 0.903 & & & \\
\hline ESC1 & 0.729 & 0.731 & 0.735 & \multirow{4}{*}{0.730} & \multirow{4}{*}{0.717} & \multirow{4}{*}{0.742} \\
\hline ESC2 & 0.870 & 0.882 & 0.868 & & & \\
\hline ESC3 & 0.913 & 0.878 & 0.933 & & & \\
\hline ESC4 & 0.895 & 0.886 & 0.898 & & & \\
\hline KIN1 & 0.868 & 0.878 & 0.841 & \multirow{4}{*}{0.756} & \multirow{4}{*}{0.797} & \multirow{4}{*}{0.737} \\
\hline KIN2 & 0.868 & 0.897 & 0.878 & & & \\
\hline KIN3 & 0.855 & 0.881 & 0.867 & & & \\
\hline KIN4 & 0.886 & 0.914 & 0.848 & & & \\
\hline PEO1 & 0.929 & 0.929 & 0.930 & \multirow{4}{*}{0.850} & \multirow{4}{*}{0.863} & \multirow{4}{*}{0.841} \\
\hline PEO2 & 0.945 & 0.950 & 0.937 & & & \\
\hline PEO3 & 0.925 & 0.934 & 0.920 & & & \\
\hline PEO4 & 0.888 & 0.902 & 0.879 & & & \\
\hline PTR1 & 0.888 & 0.945 & 0.783 & \multirow{4}{*}{0.872} & \multirow{4}{*}{0.895} & \multirow{4}{*}{0.843} \\
\hline PTR2 & 0.951 & 0.955 & 0.929 & & & \\
\hline PTR3 & 0.946 & 0.952 & 0.975 & & & \\
\hline PTR4 & 0.948 & 0.932 & 0.972 & & & \\
\hline TIN1 & 0.876 & 0.888 & 0.851 & \multirow{3}{*}{0.762} & \multirow{3}{*}{0.730} & \multirow{3}{*}{0.793} \\
\hline TIN2 & 0.842 & 0.808 & 0.885 & & & \\
\hline TIN3 & 0.900 & 0.865 & 0.934 & & & \\
\hline TPV1 & 0.867 & 0.858 & 0.861 & \multirow{3}{*}{0.789} & \multirow{3}{*}{0.784} & \multirow{3}{*}{0.777} \\
\hline TPV2 & 0.927 & 0.921 & 0.931 & & & \\
\hline TPV3 & 0.870 & 0.875 & 0.851 & & & \\
\hline
\end{tabular}


Table 5: Assessment of Discriminant Validity via HTMT

\begin{tabular}{|c|c|c|c|c|c|c|c|c|c|}
\hline Nationality & Constructs & COP & EDU & ESC & KIN & PEO & PTR & TPV & TIN \\
\hline \multirow{8}{*}{ OVERALL } & $\mathrm{COP}$ & & & & & & & & \\
\hline & EDU & 0.642 & & & & & & & \\
\hline & ESC & 0.570 & 0.542 & & & & & & \\
\hline & KIN & 0.563 & 0.510 & 0.526 & & & & & \\
\hline & PEO & 0.587 & 0.570 & 0.431 & 0.374 & & & & \\
\hline & PTR & 0.051 & 0.093 & 0.080 & 0.047 & 0.082 & & & \\
\hline & TPV & 0.399 & 0.403 & 0.436 & 0.425 & 0.533 & 0.210 & & \\
\hline & TIN & 0.259 & 0.303 & 0.261 & 0.260 & 0.311 & 0.116 & 0.565 & \\
\hline \multirow{8}{*}{$\begin{array}{c}M A L A Y- \\
\text { SIANS }\end{array}$} & $\mathrm{COP}$ & & & & & & & & \\
\hline & EDU & 0.690 & & & & & & & \\
\hline & ESC & 0.571 & 0.520 & & & & & & \\
\hline & KIN & 0.585 & 0.539 & 0.529 & & & & & \\
\hline & PEO & 0.551 & 0.634 & 0.417 & 0.356 & & & & \\
\hline & PTR & 0.119 & 0.122 & 0.100 & 0.079 & 0.106 & & & \\
\hline & TPV & 0.395 & 0.471 & 0.461 & 0.438 & 0.480 & 0.227 & & \\
\hline & TIN & 0.326 & 0.387 & 0.308 & 0.440 & 0.375 & 0.165 & 0.593 & \\
\hline \multirow{8}{*}{ TAIWANESE } & $\mathrm{COP}$ & & & & & & & & \\
\hline & EDU & 0.598 & & & & & & & \\
\hline & ESC & 0.565 & 0.551 & & & & & & \\
\hline & KIN & 0.534 & 0.467 & 0.508 & & & & & \\
\hline & PEO & 0.632 & 0.522 & 0.462 & 0.402 & & & & \\
\hline & PTR & 0.041 & 0.084 & 0.109 & 0.046 & 0.056 & & & \\
\hline & TPV & 0.490 & 0.438 & 0.531 & 0.538 & 0.630 & 0.170 & & \\
\hline & TIN & 0.244 & 0.283 & 0.282 & 0.161 & 0.246 & 0.095 & 0.486 & \\
\hline
\end{tabular}

\section{Assessment of Structural Model and Moderation Effect}

The following step was to assess the structural model after verifying validity and reliability. As highlighted in Table 6, the inner Variance Inflation Factor (VIF) was used to detect the problem of collinearity. The data showed that all items had inner VIF values below the maximum general rule of 3.33 (Diamantopoulos \& Siguaw, 2006). This shows that the model was safe from the problem of multicollinearity.

Subsequently, bootstrapping with the recommended 5,000 resamples (Hair et al., 2017) was carried out to analyse the hypotheses as well as to evaluate the value of path coefficients. The results for both Malaysian and Taiwanese respondents are highlighted in Table 6. In terms of the significance of path coefficients, escape motivation, kinship motivation, and people motivation demonstrated significant effects on perceived value for both groups of respondents, supporting H2, H4, and H5. Specifically, the full data set's results for escape motivation ( $\mathrm{H} 2: \beta=0.162, t=2.837$ ), kinship motivation (H4: $\beta=0.185, t=3.332$ ), and people motivation ( $\mathrm{H} 5: \beta=0.357, t=5.262)$; the Malaysian data set's results for escape motivation ( $\mathrm{H} 2: \beta=0.188, t=2.862)$, kinship motivation (H4: $\beta=0.174, t=2.498)$, and people motivation (H5: $\beta=0.247, t=2.602)$; and the Taiwanese data set's results for escape motivation ( $\mathrm{H} 2: \beta=0.198, t=2.254)$, kinship motivation ( $\mathrm{H} 4: \beta=0.241, t=2.984)$, and people motivation $(\mathrm{H} 5: \beta=0.402, t=3.623$ ) 
were all significant. However, the full data set's results for education motivation (H1: $\beta=0.022, t=0.366)$ and coping motivation $(\mathrm{H} 3: \beta=-0.027, t=0.429)$; the Malaysian data set's results for education motivation $(\mathrm{H} 1: \beta=0.121, t=1.248)$ and coping motivation $(\mathrm{H} 3: \beta=-0.029, t=0.352)$; and the Taiwanese data set's results for education motivation $(\mathrm{H} 1: \beta=0.006, t=0.077)$ and coping motivation $(\mathrm{H} 3: \beta=-0.019$, $t=0.199$ ) were not significant. Thus, $\mathrm{H} 1$ and $\mathrm{H} 3$ were rejected and it was concluded that education motivation and coping motivation do not affect perceived value.

For H6, the results reported that perceived value has significant effect on travel intention for the full data set (H6: $\beta=0.482, t=10.283$ ), the Malaysian data set (H6: $\beta$ $=0.486, t=8.328)$, and the Taiwanese data set (H6: $\beta=0.444, t=6.034)$. In the case of moderator testing, the moderation of perceived travel risk was found to have no significant effect on travel intention for the full data set $(\mathrm{H} 7: \beta=0.006, t=0.107)$, the Malaysian data set (H7: $\beta=-0.062, t=0.857)$, and the Taiwanese data set $(\mathrm{H} 7: \beta=0.1$, $t=1.003)$. H7 was rejected, as perceived risk does not affect the relationship between perceived value and travel intention.

The assessment of $\mathrm{R}^{2}$ illustrated that the five independent variables, education (H1), escape (H2), coping (H3), kinship (H4), and people (H5), explained 30.3\%, 29.4\%, and $42.7 \%$ of the variation in perceived value for the full data set, the Malaysian data set, and the Taiwanese data set, respectively. Perceived value describes $23.6 \%$ of variation in travel intention for the full data set, $26.3 \%$ for the Malaysian data set, and $18.7 \%$ for the Taiwanese data set. To analyse the effect size of an indicator, $\mathrm{f}^{2}$ was applied in this research and divided into three categories, where values of $0.02,0.15$, and 0.35 were defined as small, medium, and large, respectively (Cohen, 1988). According to Table 6 , escape motivation $(\mathrm{H} 2)$ and kinship motivation $(\mathrm{H} 4)$ had a small effect size on perceived value for all groups of respondents. People motivation (H5), in turn, had a small effect size on perceived value for the full data set and the Malaysian data set, but a medium effect size on perceived value for the Taiwanese data set. However, both education motivation (H1) and coping motivation (H3) exhibited little or no effect on perceived value for both respondent groups. Additionally, the data shows that perceived value has medium effect size on travel intention for all respondents. Finally, the predictive relevance, $\mathrm{Q}^{2}$, value must be above zero to show that a model possesses predictive power. All values of $\mathrm{Q}^{2}$ were more than zero in this study. Therefore, the model exhibited satisfactory predictive power. 
Table 6: Assessment of Structural Model and Moderation Effect

\begin{tabular}{lcccccccc}
\hline $\mathbf{H}$ & $\mathbf{R}$ & $\boldsymbol{\beta}$ & $\mathbf{S E}$ & $\boldsymbol{t}$ & $\mathbf{C I}$ & $\boldsymbol{f}^{2}$ & $\boldsymbol{R}^{\mathbf{2}}$ \\
\hline H1 & EDU $\rightarrow$ TPV & 0.022 & 0.060 & 0.366 & -0.077 & 0.122 & 0.000 & \\
H2 & ESC $\rightarrow$ TPV & 0.162 & 0.057 & 2.837 & 0.067 & 0.254 & 0.024 & \\
H3 & COP $\rightarrow$ TPV & -0.027 & 0.063 & 0.429 & -0.133 & 0.073 & 0.001 & 0.303 \\
H4 & KIN $\rightarrow$ TPV & 0.185 & 0.056 & 3.332 & 0.094 & 0.277 & 0.033 & \\
H5 & PEO $\rightarrow$ TPV & 0.357 & 0.068 & 5.262 & 0.246 & 0.470 & 0.116 & \\
H7 & PTR $*$ TPV $\rightarrow$ TIN & 0.025 & 0.055 & 0.452 & -0.075 & 0.106 & 0.001 & \\
\hline H1 & EDU $\rightarrow$ TPV & 0.121 & 0.097 & 1.248 & -0.040 & 0.276 & 0.010 & \\
H2 & ESC $\rightarrow$ TPV & 0.188 & 0.066 & 2.862 & 0.080 & 0.295 & 0.033 & \\
H3 & COP $\rightarrow$ TPV & -0.029 & 0.083 & 0.352 & -0.176 & 0.098 & 0.001 & \multirow{2}{*}{0.294} \\
H4 & KIN $\rightarrow$ TPV & 0.174 & 0.070 & 2.498 & 0.057 & 0.287 & 0.027 & \\
H5 & PEO $\rightarrow$ TPV & 0.247 & 0.095 & 2.602 & 0.092 & 0.403 & 0.053 & \\
H7 & PTR $*$ TPV $\rightarrow$ TIN & 0.060 & 0.065 & 0.922 & -0.056 & 0.156 & 0.005 & \\
\hline H1 & EDU $\rightarrow$ TPV & 0.006 & 0.076 & 0.077 & -0.119 & 0.129 & 0.000 & \\
H2 & ESC $\rightarrow$ TPV & 0.198 & 0.088 & 2.254 & 0.045 & 0.335 & 0.043 & \\
H3 & COP $\rightarrow$ TPV & -0.019 & 0.096 & 0.199 & -0.181 & 0.129 & 0.000 & \multirow{2}{*}{0.427} \\
H4 & KIN $\rightarrow$ TPV & 0.241 & 0.081 & 2.984 & 0.107 & 0.370 & 0.070 & \\
H5 & PEO $\rightarrow$ TPV & 0.402 & 0.111 & 3.623 & 0.221 & 0.582 & 0.171 & \\
H7 & PTR $*$ TPV $\rightarrow$ TIN & -0.042 & 0.096 & 0.436 & -0.221 & 0.093 & 0.002 & \\
\hline
\end{tabular}

Note. H: Hypothesis; R: Relationship; $\beta$ : Standardised Beta; SE: Standard Error; t: T statistics; CI: Confidence interval

\section{Assessment of Mediation Effect}

Nitzl et al. (2016) recommended the bootstrapping technique to evaluate mediation effects in a research framework. The results of the indirect effect after bootstrapping are shown in Table 7. Based on 1.960 as the threshold value of significance, perceived value was revealed to have a mediating effect between the motivation factors of escape, kinship, and people and tourists' travel intention. This was true for both respondent groups from Malaysia and Taiwan, indicating that H6b, H6d, and H6e were supported. However, perceived value did not show a mediating role in the impacts of education motivation and coping motivation on travel intention. Therefore, H6a and H6c were rejected. 
Table 7: Assessment of Mediation Effect

\begin{tabular}{ccccccc}
\hline $\mathbf{H}$ & \multicolumn{1}{c}{ MR } & $\boldsymbol{\beta}$ & $\mathbf{S E}$ & $\boldsymbol{t}$ & \multicolumn{2}{c}{ CI } \\
\hline H6a & EDU $\rightarrow$ TPV $\rightarrow$ TIN & 0.011 & 0.030 & 0.352 & -0.049 & 0.067 \\
H6b & ESC $\rightarrow$ TPV $\rightarrow$ TIN & 0.078 & 0.029 & 2.676 & 0.023 & 0.137 \\
H6c & COP $\rightarrow$ TPV $\rightarrow$ TIN & -0.013 & 0.030 & 0.427 & -0.07 & 0.049 \\
H6d & KIN $\rightarrow$ TPV $\rightarrow$ TIN & 0.089 & 0.029 & 3.126 & 0.032 & 0.143 \\
H6e & PEO $\rightarrow$ TPV $\rightarrow$ TIN & 0.172 & 0.035 & 4.85 & 0.102 & 0.237 \\
\hline H6a & EDU $\rightarrow$ TPV $\rightarrow$ TIN & 0.059 & 0.050 & 1.181 & -0.034 & 0.167 \\
H6b & ESC $\rightarrow$ TPV $\rightarrow$ TIN & 0.091 & 0.034 & 2.71 & 0.03 & 0.166 \\
H6c & COP $\rightarrow$ TPV $\rightarrow$ TIN & -0.014 & 0.039 & 0.363 & -0.085 & 0.060 \\
H6d & KIN $\rightarrow$ TPV $\rightarrow$ TIN & 0.085 & 0.037 & 2.285 & 0.013 & 0.150 \\
H6e & PEO $\rightarrow$ TPV $\rightarrow$ TIN & 0.120 & 0.050 & 2.424 & 0.036 & 0.220 \\
\hline H6a & EDU $\rightarrow$ TPV $\rightarrow$ TIN & 0.003 & 0.034 & 0.077 & -0.068 & 0.071 \\
H6b & ESC $\rightarrow$ TPV $\rightarrow$ TIN & 0.088 & 0.043 & 2.062 & 0.014 & 0.175 \\
H6c & COP $\rightarrow$ TPV $\rightarrow$ TIN & -0.009 & 0.041 & 0.207 & -0.095 & 0.066 \\
H6d & KIN $\rightarrow$ TPV $\rightarrow$ TIN & 0.107 & 0.039 & 2.712 & 0.020 & 0.182 \\
H6e & PEO $\rightarrow$ TPV $\rightarrow$ TIN & 0.178 & 0.052 & 3.413 & 0.081 & 0.283 \\
\hline
\end{tabular}

Note. H: Hypothesis; MR: Mediating Relationship; $\beta$ : Standardised Beta; SE: Standard Error; t: T statistics; CI: Confidence interval

\section{Discussion}

The current study has successfully discovered several noteworthy findings. First, the results show that education motivation does not motivate Malaysian or Taiwanese respondents to value travel, contradicting past studies that have examined travel motivation (Fisher \& Price, 1991; Yoo et al., 2018). Based on the findings relating travel motivation to intercultural interaction (Cham \& Easvaralingam, 2012; Fisher \& Price, 1991), education motivation may only be significant in view of cross-cultural communication. However, it is not one of the factors travellers consider in the controlled pandemic situation. As technologies are advancing, education can be gained through online or virtual meetings and is not restricted to any place or country. Travellers thus do not see the need to travel for the sake of education, as their health is more important during this period of time. Besides, most colleges and universities are implementing e-Learning, while the Internet is also able to provide boundless information and resources at the click of a search button.

Second, it was found that escape motivation drives both Malaysian and Taiwanese travellers to develop the intention to travel via perceived value. One of the biggest reasons is that they are tired of their lifestyle or working life under lockdown. They may also be having countless emotional battles within their head, the stress of which they want to release by going on a trip that helps them relax and escape from routine life when traveling is permitted (Shanmugam et al., 2020). This shows that travellers see escape motivation as part of their perceived value and are willing to travel if the pandemic is under control (i.e., SOPs are well-implemented).

Third, the findings indicate that coping motivation affects neither Malaysian nor Taiwanese respondents to have the intention to travel. This result is consistent with past research (Levitt, 2019). Although travelling can offer an objective view of what has 
happened around them, there may be other factors which are more important than coping during the pandemic. For example, factors concerning their health or the health of their families are more significant to tourists than travelling to cope with life. Therefore, they do not perceive coping as a travel motivation in the context of the pandemic.

Fourth, kinship is especially important during this pandemic. In line with this, our findings reveal that people are motivated to travel or plan small trips to meet their families and relatives who live in different countries or states. Due to the border travel restriction during the pandemic, many people could not go back to their hometowns for semester break or special celebrations like Chinese New Year. The desire to meet and spend quality time with their families is now higher after not meeting one another for an extended period of time. According to Shanmugam et al. (2020), family support and relationship is vital to reduce mental health issues during the pandemic. Therefore, kinship is one of the most highly perceived values of travel and facilitates the intention to travel.

Fifth, the results show that people motivation promotes and enhances perceived value and the intention to travel. Due to the pandemic, lockdowns and large gatherings were restricted to reduce the risk of COVID-19 infection. During this period, people became disconnected from human contact. Although they could still meet new friends virtually, the downside is that virtual friendships lack human interaction and eye contact. Thus, people are realising the importance of socialising, getting to know new friends, hanging out, and communicating with others whose opinions are different. Thus, the desire to meet and interact with new people is getting stronger.

Next, the results show that travellers' perceived value can affect their travel intention, which is consistent with past studies (Suhartanto et al., 2019; Prebensen \& Xie, 2017). If tourists perceive that travelling in the controlled pandemic scenario will benefit them in terms of escape, people, and kinship, they will have a high intention to travel. Therefore, the S-O-R theory is proven to be suitable in this research, whereby the organism (perceived value) and response (travel intention) are affected by the stimulus (motivation). For example, when travellers perceive that returning to their hometown allows them to meet and spend time with their family, they will have the intention to travel even during the pandemic.

As for the moderation effect, perceived travel risk does not weaken the relationship between perceived value and travel intention among both Malaysian and Taiwanese respondents. However, this does not imply that perceived travel risk is unimportant; rather, perceptions of travel risk will vary based on the situation the respondents are in. One of the reasons COVID-19 does not have big impact on Taiwanese respondents is because the situation is less severe in their country. Taiwan has fewer local positive cases and is seen as one of the best countries in handling the outbreak. Their government took quick and strict actions in implementing their SOPs during the outbreak of COVID-19 due to its past experience with SARS, bird flu, and H1N1 (Summers et al., 2020). As for Malaysia, perhaps one of the main reasons for lower perceived risk is because the pandemic situation was less serious at the time the data was collected. Although it became serious over time, the administering of vaccinations give Malaysian and Taiwanese travellers a renewed hope that they would be able to travel freely soon. Despite the spread of Omicron and the concerns about the emergence of more deadly 
variants, many Malaysians and Taiwanese take the calculated risk to travel due to the aforementioned motivation factors and perceived value.

\section{Implications for Asian Business}

In terms of theoretical contribution, this research expanded the S-O-R model by revealing how motivational factors enhance perceived value and thus, influence travel intention. Motivation acts as the stimulus, which we decomposed into five components to provide more insight into and understanding of travel motivation in the context of the pandemic. Through this study, escape, kinship, and people motivation were found to enhance perceived value and consequently, the intention of respondents to travel when the pandemic is under control. However, education and coping motivation do not affect perceived value and travel intention. Therefore, even during this pandemic crisis, Malaysians and Taiwanese in general still want to travel and see the value of travelling, which is to escape, spend time with family, or make new friends and socialise.

In addition, the S-O-R model was further extended by incorporating a contingent variable, i.e., perceived travel risk. The notion of perceived travel risk is supported by the Uncertainty Avoidance Theory. We advocate that perceived travel risk relies on the situation, namely its traits and seriousness. When the situation is less serious, perceived travel risk has little effect, whereas when the situation is severe, perceived travel risk increases. Situational factors also include vaccination programs and health measures. Besides, traveling is almost a second nature to many individuals. Nonetheless, travellers maintain the intention to travel if the situation allows, as they still perceive value in travelling or going on a trip.

In terms of managerial implications, governments and tour operators in Asia can take this chance to revive and promote domestic tourism, which is expected to recover first from the outbreak of COVID-19. This would not only provide a short getaway and allow people to connect with local communities, but also enable families to strengthen their bonding time with one another. Notably, local governments need to be strict with their SOPs and quick to act so that citizens know it is safe for them to travel across cities and states. Indeed, travellers may escape from their busy city life to a rural area for a short vacation or explore different places to learn about nature and culture. As such, the government can encourage community-based tourism or programmes that promote homestay and cultural heritage to support the local community and build the domestic economy.

Furthermore, the governments, tourism agencies and travel businesses in Asia can continue the expansion of their "travel bubble" implementation with trust and care. Despite being a complex task, many countries in Asia have started and are working out plans to cooperate and connect internationally (Luo \& Lam, 2020; Yusof, 2021). Although travellers are restricted in choosing their travel destinations, the travel bubble still provides an opportunity for them to escape from their stressful life. When the pandemic is under control, the governments can further reinforce travel bubbles with the neighbouring countries and other important destinations. It thus underscores the will to cooperate between governments, tourism ministries, airline companies and world travel bodies, such as World Tourism Organisation (UNWTO), International Air Transport Association (IATA) and Pacific Asia Travel Association (PATA) (Fusté-Forné \& Michael, 2021). 
Lastly, a transparent and standardised cross-border SOPs may ease travelling. The findings show that travellers are still willing to travel as long as they see the value of the trip and SOPs are well implemented. Nevertheless, travellers might not be clear about certain guidelines and thus fail to comply. Therefore, destination operators and travel agencies need to work closely with the government to ensure all standardised cross-border SOPs are well-obeyed. With this, the government can reduce the risk of travellers and local community members being exposed to the pandemic, and travellers may move freely within permitted regions. This highlights the importance of responsible travel, and tourism and the urgency for all relevant stakeholders to collaborate to ensure health and safety are in place in the controlled pandemic context (Cheer et al., 2020; Ting et al., 2021).

\section{References}

Beard, J. G. \& Ragheb, M. G. (1983). Measuring leisure motivation. Journal of Leisure Research, 15(3), 219-228, https://doi.org/10.1080/00222216.1983.11969557.

Boholm, A. (1998). Comparative studies of risk perception: A review of twenty years of research. Journal of Risk Research, 1(2), 135-163, https://doi.org/10.1080/136698798377231.

Brouder, P., Teoh, S., Salazar, N., Mostafanezhad, M., Pung, J., Lapointe, D., . . . Clausen, H. (2020). Reflections and discussions: tourism matters in the new normal post COVID19. Tourism Geographies, 22(3), 735-746.

Cahyanto, I., Wiblishauser, M., Pennington-Gray, L., \& Schroeder, A. (2016). The dynamics of travel avoidance: The case of Ebola in the US. Tourism Management Perspectives, 20, 195-203, https://doi.org/10.1016/j.tmp.2016.09.004.

Cao, X. (2019). The motivation of the Chinese post-90s generation for travelling abroad, http://hdl.handle.net/10063/8688.

Cham, T. H., \& Easvaralingam, Y. (2012). Service quality, image and loyalty towards Malaysian hotels. International Journal of Services, Economics and Management, 4(4), 267-281.

Cham, T. H., Cheng, B. L., Low, M. P. and Cheok, J. B. C. (2020). Brand Image as the competitive edge for Hospitals in Medical Tourism. European Business Review, 31(1), 31-59.

Cham, T. H., Lim, Y. M., Sia, B. C., Cheah, J. H., \& Ting, H. (2021a). Medical tourism destination image and its relationship with the intention to revisit: A study of Chinese medical tourists in Malaysia. Journal of China Tourism Research, 17(2), 163-191.

Cham, T. H., Cheng, B. L. and Ng, C. K. Y. (2021b). Cruising down millennials' fashion runway: a cross-functional study beyond Pacific borders. Young Consumers, 22(1), 2867.

Cheer, J.M., Ting, H. \& Leong, C.M. (2021). Responsible Tourism: A New Era of Responsibility?, Journal of Responsible Tourism Management, 1(1), 1-17, https://doi.org/10.47263/JRTM.01-01-01.

Chen, X., Cheng, Z.-f., \& Kim, G.-B. (2020). Make It Memorable: Tourism Experience, Fun, Recommendation and Revisit Intentions of Chinese Outbound Tourists. Sustainability 12(5), 1904, https://doi.org/10.3390/su12051904.

Cheng, B. L., Shaheen, M., Cham, T. H., Dent, M. M., \& Yacob, Y. (2021). Building Sustainable Relationships: Service Innovation at the Pinnacle of Touristic Achievement. Asian Journal of Business Research, 11(1), 80-90.

Chin, W., Cheah, J. H., Liu, Y., Ting, H., Lim, X. J., \& Cham, T. H. (2020). Demystifying the role of causal-predictive modeling using partial least squares structural equation modeling in information systems research. Industrial Management \& Data Systems, 120(12), 2161-2209, https://doi.org/10.1108/IMDS-10-2019-0529. 
Cohen, E. (1972). Toward a sociology of international tourism. Social Research, 39(1), 164182, http://www.jstor.org/stable/40970087.

Cohen, J. (1988). Statistical Power Analysis for the Behavioral Sciences 2nd Edition. Hillsdale, N.J.: Lawrence Erlbaum Associates, Inc.

Connor, P. (2020, April 1). More than nine-in-ten people worldwide live in countries with travel restrictions amid COVID-19. Retrieved from https://www.pewresearch.org/facttank/2020/04/01/more-than-nine-in-ten-people-worldwide-live-in-countries-withtravel-restrictions-amid-covid-19/

Crompton, J. L. (1979). Motivations for pleasure vacation. Annals of Tourism Research, 6(4), 408-424, https://doi.org/10.1016/0160-7383(79)90004-5.

Dann, G. M. (1981). Tourist motivation: An appraisal. Annals of Tourism Research, 8(2), $187-$ 219, https://doi.org/10.1016/0160-7383(81)90082-7.

Davies. (2020, March 24). The last global crisis didn't change the world. But this one could. Retrieved from The

Guardian: https://www.theguardian.com/commentisfree/2020/mar/24/coronavirus-crisis-changeworld-financial-global-capitalism

Dayak Daily. (2020, May 4). Woman falls to her death from condominium at Jalan Wan Alwi. Retrieved from Dayak Daily: https://dayakdaily.com/woman-falls-to-her-death-fromcondominium-at-jalan-wan-alwi/

Diamantopoulos, A., \& Siguaw, J. A. (2006). Formative versus reflective indicators in organizational measure development: a comparison and empirical illustration. British Journal of Management, 17(4), 263-282, https://doi.org/10.1111/j.14678551.2006.00500.x.

Faul, F., Erdfelder, E., Buchner, A. and Lang, A.G. (2009), "Statistical power analyses using G* Power 3.1: Tests for correlation and regression analyses", Behavior research methods, Vol. 41 No. 4, pp. 1149-1160.

Fisher, R. J., \& Price, L. L. (1991). International Pleasure Travel Motivations and Post-Vacation Cultural Attitude Change. Journal of Leisure Research, 23(3), 193-208, https://doi.org/10.1080/00222216.1991.11969853.

Fusté-Forné, F., \& Michael, N. (2021). Limited tourism: travel bubbles for a sustainable future. Journal of $\quad$ Sustainable $\quad$ Tourism, $1-18$. https://doi.org/10.1080/09669582.2021.1954654

García-Fernández, J., Gálvez-Ruíz, P., Fernández-Gavira, J., Vélez-Colón, L., Pitts, B., \& Bernal-García, A. (2018). The effects of service convenience and perceived quality on perceived value, satisfaction and loyalty in low-cost fitness centers. Sport Management Review, 21(3), 250-262, https://doi.org/10.1016/j.smr.2017.07.003.

Goodell, J. W. (2020). COVID-19 and finance: Agendas for future research. FInance Research Letters, 35, 101512.

Gössling, S., Scott, D., \& Hall, C. M. (2020). Pandemics, tourism and global change: a rapid assessment of COVID-19. Journal of Sustainable Tourism, 29(1), 1-20.

Hair, J. F., Hult, G. T., Ringle, C. M., \& Sarstedt, M. (2017). A Primer on Partial Least Squares Structural Equation Modeling (PLS-SEM) 2nd edition. Thousand Oaks, CA: Sage Publications, Inc.

Han, H., Meng, B., Chua, B.-L., Ryu, H. B., \& Kim, W. (2019). International volunteer tourism and youth travelers - an emerging tourism trend. Journal of Travel \& Tourism Marketing, 36(5), 549-562, https://doi.org/10.1080/10548408.2019.1590293.

Hofstede, G. (2001). Culture's Consequences: Comparing Values, Behaviors, Institutions, and Organizations Across Nations, 2nd edition. Thousand Oaks, CA: Sage Publications.

Hu, X., Huang, Q., Zhong, X., Davison, R. M., \& Zhao, D. (2016). The influence of peer characteristics and technical features of a social shopping website on a consumer's purchase intention. International Journal of Information Management, 36(6), 12181230, https://doi.org/10.1016/j.ijinfomgt.2016.08.005.

Iso-Ahola, S.E. (1983). Towards a social psychology of recreational travel, Leisure Studies, 2(1), 45-56, https://doi.org/10.1080/02614368300390041. 
Kara, N. S., \& Mkwizu, K. H. (2020). Demographic factors and travel motivation among leisure tourists in Tanzania. International Hospitality Review, 34(1), 81-103, https://doi.org/10.1108/IHR-01-2020-0002.

Khan, M. J., Chelliah, S., \& Ahmed, S. (2017). Factors influencing destination image and visit intention among young women travellers. Asia Pacific Journal of Tourism Research, 22(11), 1139-1155, https://doi.org/10.1080/10941665.2017.1374985.

Khan, S. (2020). COVID-19: Tourism at Crossroads! Where Next? Journal on Tourism \& Sustainability, 3(2), 32-40.

Lee, C., Song, H., Bendle, L. J., Kim, M., \& Han, H. (2012). The impact of non-pharmaceutical interventions for 2009 H1N1 influenza on travel intentions: A model of goal-directed $\begin{array}{llll}\text { behavior. } & \text { Tourism } & \text { Management, } & \text { 33(1), }\end{array}$ https://doi.org/10.1016/j.tourman.2011.02.006.

Lee, H. J., \& Yun, Z. S. (2015). Consumers' perceptions of organic food attributes and cognitive and affective attitudes as determinants of their purchase intentions toward organic food. Food quality and preference, 39, 259-267, https://doi.org/10.1016/j.foodqual.2014.06.002.

Levitt, J. A., Zhang, P., DiPietro, R. B., \& Meng, F. (2019). Food tourist segmentation: Attitude, behavioral intentions and travel planning behavior based on food involvement and motivation. International Journal of Hospitality \& Tourism Administration, 20(2), 129155.

Lim, X. J, Ng, S. I, Chuah, F., Cham, T. H., \& Rozali, A. (2019). I see, and I hunt: The link between gastronomy online reviews, involvement and behavioural intention towards ethnic food. British Food Journal, 122(6), 1777-1800.

Luo, J. M., \& Lam, C. F. (2020). Travel anxiety, risk attitude and travel intentions towards "travel bubble" destinations in Hong Kong: Effect of the fear of COVID19. International journal of environmental research and public health, 17(21), 7859.

Maser, B., \& Weiermair, K. (1998). Travel decision-making: From the vintage point of perceived risk and information preferences. Journal of Travel \& Tourism Marketing, 7(4), 107-121, https://doi.org/10.1300/J073v07n04_06.

Mehrabian, A., \& Russell, J. (1974). An Approah to Environmental Psychology. Cambridge, USA: The MIT Press.

Neuburger, L., \& Egger, R. (2021). Travel risk perception and travel behaviour during the COVID-19 pandemic 2020: A case study of the DACH region. Current Issues in Tourism, 24(7), 1003-1016, https://doi.org/10.1080/13683500.2020.1803807.

Nicola, M., Alsafi, Z., Sohrabi, C., Kerwan, A., Al-Jabir, A., Iosifidis, C., Agha, M., \& Agha, R. (2020). The socio-economic implications of the coronavirus pandemic (COVID-19): A review. International journal of surgery, 78, 185-193. https://doi.org/10.1016/j.ijsu.2020.04.018.

Nitzl, C., Roldan, J. L., \& Cepeda, G. (2016). Mediation analysis in partial least squares path modeling: Helping researchers discuss more sophisticated models. Industrial Management and Data Systems, 116(9), 1849-1864, https://doi.org/10.1108/IMDS-072015-0302.

OECD. (2020, June 2). Tourism Policy Responses to Coronavirus (COVID-19). Retrieved from https://www.oecd.org/coronavirus/policy-responses/tourism-policy-responses-to-thecoronavirus-covid-19-6466aa20/

Peter, J. P., \& Olson, J. C. (1996). Consumer Behavior and Marketing Strategy (5th ed.). Toronto: Irwin McGraw-Hill.

Pine, R., \& McKercher, B. (2004). The impact of SARS on Hong Kong's tourism industry. International Journal of Contemporary Hospitality Management, 16(2), 139-143, https://doi.org/10.1108/09596110410520034.

Prebensen, N. K., \& Xie, J. (2017). Efficacy of co-creation and mastering on perceived value and satisfaction in tourists' consumption. Tourism Management 60 (2017) 166-176, http://dx.doi.org/10.1016/j.tourman.2016.12.001.

Pyo, S., Mihalik, B. J., \& Uysal, M. (1989). Attraction attributes and motivations: A canonical correlation analysis. Annals of Tourism Research, 16(2), 277-282. 
Sarstedt, M., \& Cheah, J. H. (2019). Partial least squares structural equation modeling using SmartPLS: a software review, Journal of Marketing Analytics, 7, 196-202, https://doi.org/10.1057/s41270-019-00058-3.

Saunders, M., Lewis, P. and Thornhill A. (2012), Research Methods for Business Students $\left(6^{\text {th }}\right.$ Edition), Pearson, UK.

Shanmugam, H., Juhari, J. A., Nair, P., Ken, C. S., \& Guan, N. C. (2020). Impacts of COVID19 Pandemic on Mental Health in Malaysia: A Single Thread of Hope. Malaysian Journal of Psychiatry, 29(1), 78-84.

Shin, H., \& Kang, J. (2020). Reducing perceived health risk to attract hotel customers in the COVID-19 pandemic era: Focused on technology innovation for social distancing and cleanliness. International Journal of Hospitality Management, 91, 102664, https://doi.org/10.1016/j.ijhm.2020.102664.

Sönmez, S. F. (1998). Tourism, terrorism, and political instability. Annals of tourism research, 25(2), 416-456, https://doi.org/10.1016/S0160-7383(97)00093-5.

Sönmez, S. F., \& Graefe, A. R. (1998). Determining future travel behavior from past travel experience and perceptions of risk and safety. Journal of travel research, 37(2), 171177, https://doi.org/10.1177\%2F004728759803700209.

Suhartanto, D., Brien, A., Primiana, I., Wibisono, N., \& Nyoman, N. (2019). Tourist loyalty in creative tourism: the role of experience quality, value, satisfaction, and motivation. Current Issues in Tourism, 23(7), 867-879, https://doi.org/10.1080/13683500.2019.1568400.

Summers, D. J., Cheng, D. H.-Y., Lin, P. H.-H., Barnard, D. L., Kvalsvig, D. A., Wilson, P. N., \& Baker, P. M. (2020). Potential lessons from the Taiwan and New Zealand health responses to the COVID-19 pandemic. The Lancet Regional Health - Western Pacific, 4 (2020) 100044, https://doi.org/10.1016/j.lanwpc.2020.100044.

Ting, H., Morrison, A., Leong, C.M., Kumarusamy, R. \& Leong, Ql.L. (2021). Responsibility, Responsible Tourism, and Our Response. Journal of Responsible Tourism Management, 1(2), 1-9, https://doi.org/10.47263/JRTM.01-02-01.

Tinsley, H. E., \& Kass, R. A. (1978). Leisure activities and need satisfaction: A replication and extension. Journal of Leisure Research, 10(3), 191-202, https://doi.org/10.1080/00222216.1978.11969353.

Totsune, T., Matsudaira, I., \& Taki, Y. (2021). Curiosity-tourism interaction promotes subjective wellbeing among older adults in Japan. Humanities and Social Sciences Communications, 8(1), 1-11.

Turnsek, M., Brumen, B., Rangus, M., Gorenak, M., Mekinz, J., \& Stuhec, T. L. (2020). Perceived Threat of COVID-19 and Future Travel Avoidance. Original Scientific Article, 4, https://doi.org/10.26493/2335-4194.13.3-19.

UNWTO. (2020, April 17). Covid-19 response: $96 \%$ of global destinations impose travel restrictions. Retrieved from https://www.unwto.org/news/covid-19

Weinstein, N. D. (1988). The precaution adoption process. Health Psychology, 7(4), 355-386, https://psycnet.apa.org/doi/10.1037/0278-6133.7.4.355.

Woodside, A. G., \& Jacobs, L. W. (1985). Step two in benefit segmentation: Learning the benefits realized by major travel markets. journal of Travel Research, 24(1), 7-13, https://doi.org/10.1177\%2F004728758502400102.

Worldometer. (2021, November 25). COVID-19 Coronavirus Pandemic. Retrieved from Worldometer: https://www.worldometers.info/coronavirus/\#countries

Worldometer. (2021, November 25). Coronavirus Cases Malaysia. Retrieved from Worldometer: https://www.worldometers.info/coronavirus/country/malaysia/

Worldometer. (2021, November 25). Coronavirus Cases Taiwan. Retrieved from Worldometer: https://www.worldometers.info/coronavirus/country/taiwan/

Xiao, L., Guo, F., Yu, F., \& Liu, S. (2019). The Effects of Online Shopping Context Cues on Consumers' Purchase Intention for Cross-Border E-Commerce Sustainability. Sustainability, 11(10), 2777, https://doi.org/10.3390/su11102777.

Yoo, C., Yoon, D., \& Park, E. (2018). Tourist motivation: an integral approach to destination choices. Tourism Review, https://doi.org/10.1108/TR-04-2017-0085. 
Yusof, T. A. (2021, February 6). Green light for Malaysia-Indonesia travel bubble. Retrieved from New Straits Times: https://www.nst.com.my/news/nation/2021/02/663654/green-light-malaysiaindonesia-travel-bubble

Zufara, A. Z. \& Fitriya, A. R. (2019). Malaysia vs Thailand Millennial Travellers: Understanding the Behaviour and Pattern of Young Tourists. Journal of Marketing Advances and Practices, 1(2), 25-37. 